\title{
Teaching Evaluation of Modern Chinese History Courses for Different Majors
}

\author{
Huijun Zhou \\ College of Marxism, Yangzhou University, Yangzhou, China
}

Email address:

hjzhou@yzu.edu.cn

To cite this article:

Huijun Zhou. Teaching Evaluation of Modern Chinese History Courses for Different Majors. History Research. Vol. 7, No. 2, 2019, pp. 27-31. doi: 10.11648/j.history.20190702.11

Received: September 18, 2019; Accepted: September 26, 2019; Published: October 10, 2019

\begin{abstract}
Only by understanding history can we correctly understand and grasp the objective laws of social development. Taking the teaching of the Modern Chinese History as the background, this study explores the actual academic performance of 967 students in 27 classes of 11 different majors, including: Clinical medicine, Chinese and western integrative medicine, Pharmacy, Bioscience, Bioengineering, Medical laboratory technology, Animal nutrition and feed science, Aquaculture, Pratacultural science, Ecology as well as Landscape architecture, in Yangzhou University of China. We mainly investigate the influence of the same teaching method on different majors by means of statistical analysis. The results show that the current teaching methods have a significant impact on the teaching effect of three majors: Bioengineering, Pratacultural science and Ecology. This means that the ratio of impact of the same teaching methods to different majors accounts for $27.27 \%$. In addition, we also find that there are significant differences between Bioengineering and other five majors, such as Clinical Medicine, Chinese and Western integrative medicine, Animal nutrition and feed science, Aquaculture as well as Pratacultural science. It is hoped that the analysis results of this paper may provide some theoretical basis and reference for the study of historical teaching methods, and also provide relevant information for overseas modern Chinese history research institutions to understand the learning situation of history of China in this period.
\end{abstract}

Keywords: Modern Chinese History, Teaching Evaluation, Gaussian Distribution

\section{Introduction}

China's modern history usually refers to a period of history that started in the late Qing Dynasty and faced domestic and foreign troubles. The specific time span varies slightly in the works of different periods and scholars. However, it is generally acknowledged that it has a history of nearly 180 years since the first Opium War in 1840. As far as its mainstream and essence are concerned, it is a history of heroic struggle and arduous exploration by generations of Chinese people and people with lofty ideals to save the nation from extinction [1-5]. After several years of teaching the course "Modern Chinese History", it seems difficult for us to feel that today's college students have formed a correct outlook on history. Therefore, it is an urgent and practical problem to strengthen the education of young people, especially college students, on the correct view of history.

Starting from the fall semester of 2006, colleges and universities across China began to offer the course "Modern
Chinese History" to undergraduate students. This decision was made by the Central Committee of the Communist Party of China (CPC) (see [6] for more details). This is considered to be of great significance to strengthen the ideological and political education of undergraduate students [7]. Undergraduate students are the new force for the future of every country. In order to successfully undertake the responsibility of building the country, they must understand their national characteristics, not only to understand "today", but also to understand "yesterday" and "the day before yesterday". The course provides undergraduates with a clear and concise summary of modern Chinese history [8], mainly examines China's modern and contemporary history from the perspective of world history, paying attention to the characteristics of the times, the international situation and the general trend of the world. In addition to political history, it also reflects the development of China's modern culture, economy, science and technology. Through the course, people can deepen their understanding of the laws governing the 
development of modern Chinese society, thereby inheriting and carrying forward the fine traditions of China, and improving their ability to use dialectical views and methods to analyze and solve practical problems.

The rise of China as a world power is undoubtedly one of the most important events of the 21 st century. However, as with this process, dramatic and earth-shattering, it is by no means intended. Why are students now able to sit down quietly and learn various professional skills? In just less than one century ago, China was dismissed as the "sick Asian". Some other countries talked about "the carving of the Chinese melon". The Chinese compared their country with a hopeless situation "People are knife and cutting board, we are fish and meat" and were cut into pieces by greedy whites and Japanese [9].

Our grasp of modern and contemporary history will greatly enrich our understanding of the present [10]. As the saying goes, taking history as a mirror, you always be conscious of not making the same mistake twice. It will also help students to understand the process of self-awareness that the Chinese people have experienced in the process of near-death and resurrection of the nation [9]. Therefore, for undergraduate students who were once defined as "petty bourgeoisie" [11], no matter what majors they are studying now, and what kind of professional work they will do in the future, it is necessary to study the course. However, in the actual teaching mode, does teaching different professions have significantly different effects? Is there a significant difference in the understanding of this course in different professional backgrounds? Other studies on the modern Chinese history can be found in the [12-16] and the references therein.

The purpose of this paper is to analyze the examination results of 967 undergraduate students from Yangzhou University in the history course "Modern Chinese History" during the past three years, and to study whether there are significant differences among students of different majors. The paper mainly covers 11 different majors in 27 classes, including: Clinical medicine (CM), Chinese and western integrative medicine (CWIM), Pharmacy (P), Bioscience (BS), Bioengineering (BE), Medical laboratory technology (MLT), Animal nutrition and feed science (ANFS), Aquaculture (A), Pratacultural science (PS), Ecology (E) as well as Landscape architecture (LA).

\section{Research Methods and Results Analysis}

Theoretically, only a small number of students have very excellent or bad scores, and most of them do not. This phenomenon is what statisticians call normal distribution. Therefore, we first use histogram to detect whether the distribution of their scores is abnormal. Here histogram is a statistical report graph, which represents the distribution of data by a series of longitudinal stripes or lines of varying heights. In general, the data type is represented by the horizontal axis, and the longitudinal axis represents the distribution. It is a bar chart. In order to construct a histogram, the first step is to segment the range of a fraction into a series of intervals, and then calculate how many values are in each interval. Histograms can also be normalized to show "relative" frequencies. The purpose of histogram is to observe the shape of the graph to determine whether the student's performance is stable. From Figure 1, we can see that the histogram of 967 students' scores involved in this paper agrees well with the normal distribution density curve (red dashed line). The majority of the students scored about 80 points, while the number of students who scored more than 90 points and less than 70 points was relatively small.

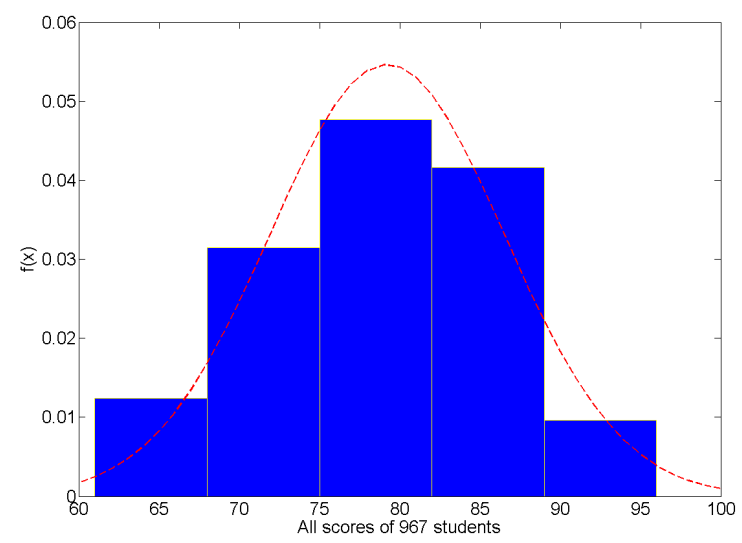

Figure 1. Frequency histogram and theoretical normal distribution PDF curve.
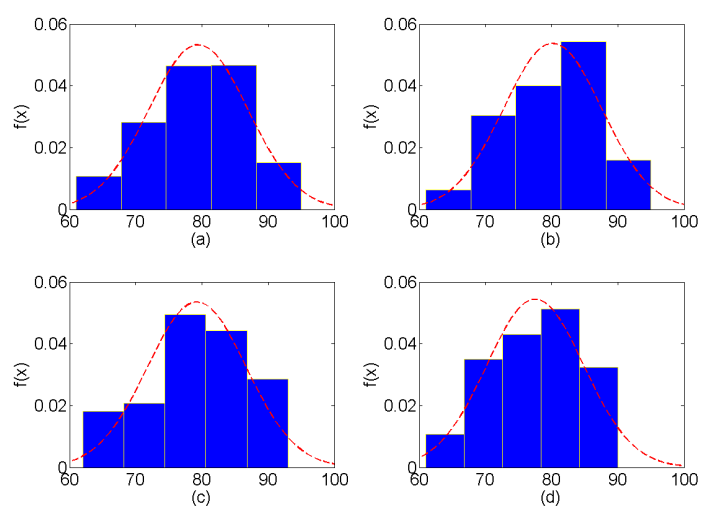

Figure 2. Frequency histograms and theoretical normal distribution PDF curves for different majors: (a) Clinical medicine (b) Chinese and western integrative medicine (c) Pharmacy (d) Bioscience.
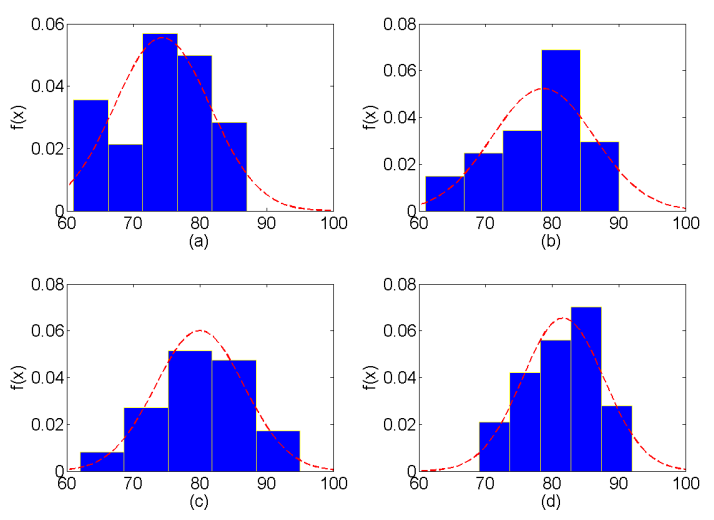

Figure 3. Frequency histograms and theoretical normal distribution PDF curves for different majors: (a) Bioengineering (b) Medical laboratory technology (c) Animal nutrition and feed science (d) Aquaculture. 

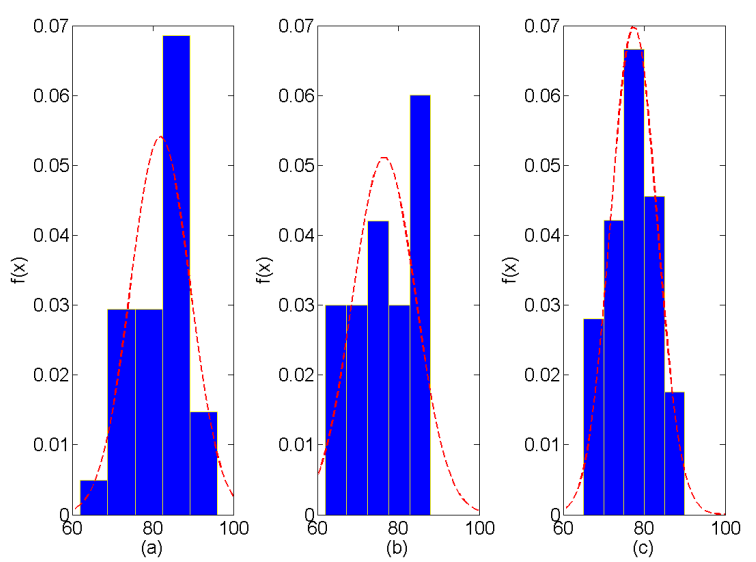

Figure 4. Frequency histograms and theoretical normal distribution PDF curves for different majors: (a) Pratacultural science (b) Ecology (c) Landscape architecture.

However, if it is differentiated by major categories (see Figures 2-4 for details), the performance of students majoring in Bioengineering in Figure 3 (a) and Pratacultural science as well as Ecology in Figures 4 (a) and 4 (b) is slightly abnormal. This can also be verified by the empirical cumulative distribution function (CDF) diagram, which is often regarded as the bridge between theoretical distribution function and actual data. It can be found that there is a clear distinction between cyan, light blue, purple line charts and other colors in Figure 5. Those line charts of the remaining colors are generally similar, and the corresponding student scores are considered to be subject to the same distribution.

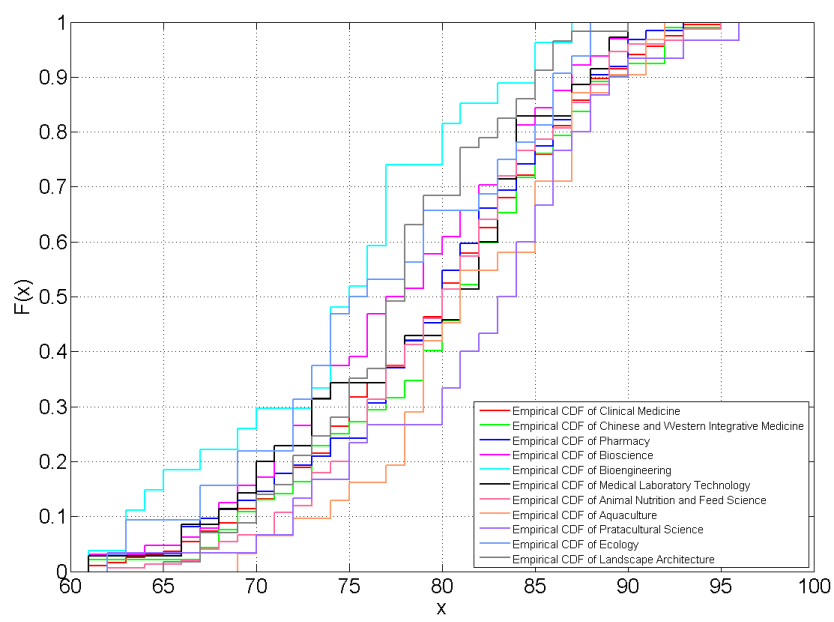

Figure 5. Empirical cumulative distribution function diagrams of different majors.

Furthermore, it can also be seen from group summary table (see Table 1) that the mean scores of students majoring in Bioengineering, Pratacultural science and Ecology are $74.3333,81.8667$ and 76.5 , respectively, which are obviously different from the pooled mean value of 79.2089. Although the mean score of Aquaculture is 81.6452, which is very close to that of Pratacultural science, the scores are relatively concentrated, which can be explained by their standard deviation 6.0858 .
Table 1. Group Summary.

\begin{tabular}{llll}
\hline Major Name & Count & Mean & Std Dev \\
\hline CM & 387 & 79.447 & 7.486 \\
CWIM & 92 & 80.1522 & 7.4228 \\
P & 62 & 79.2258 & 7.4469 \\
BS & 64 & 77.5156 & 7.3247 \\
BE & 27 & 74.3333 & 7.1737 \\
MLT & 35 & 78.6571 & 7.6194 \\
ANFS & 150 & 79.96 & 6.6301 \\
A & 31 & 81.6452 & 6.0858 \\
PS & 30 & 81.8667 & 7.3706 \\
E & 32 & 76.5 & 7.7958 \\
LA & 57 & 77.4211 & 5.7038 \\
Pooled & 967 & 79.2089 & 7.2075 \\
$p$-value & 0.37218 & & \\
\hline
\end{tabular}

In addition, we noticed that there is another indicator in the last row of Table 1 called $p$-value, which is the basis for judging whether our hypothesis (usually called null hypothesis) holds, because mathematical expectations are based on the null hypothesis. If the observed values are more consistent with the expected values, the closer the test results are to the null hypothesis, the less reason to reject the null hypothesis. If the observation value deviates from the expected value, the more the null hypothesis cannot withstand the rebuttal, the more reason to reject the null hypothesis, and thus to deduce the establishment of the alternative hypothesis. Most of the time, we assume that the probability of false rejection of the null hypothesis is 0.05 , so if the $p$-value is less than 0.05 , indicating that the probability of false rejection of the null hypothesis is very low, then we have reason to believe that the null hypothesis itself is wrong, rather than caused by the test error. Here $p$-value is often used to test the relationship between independent variables and input variables.

The null hypothesis in the present paper is that there is no relationship between them. So if the $p$-value is less than 0.05 , the null hypothesis is not valid, or that there is no relationship between the two, and the alternative hypothesis is deduced. In other words, the null hypothesis in Table 1 is that the test scores of students in different majors obey the normal distribution with the same variance, while the alternative hypothesis obeys the normal distribution with different variances. From the test results, it can be seen that the $p$-value of the test is 0.37218 , which is greater than 0.05 , indicating that the null hypothesis is accepted at the significance level of 0.05 . It is considered that the scores of students in different majors obey the normal distribution with the same variance, that is, the basic hypothesis of variance analysis is satisfied.

The following test (Analysis of Variance or ANOVA) is whether there are significant differences in the test scores of students from different majors. The null hypothesis is not significantly different, and the alternative hypothesis is significantly different. The returned $p$-value from Table 2 is $1.3115 \mathrm{e}-004$, which is much smaller than the threshold value 0.05 of significance level. Therefore, we reject the null hypothesis and believe that there is a very significant difference in the test scores of students from different majors. This conclusion can also be found from the box chart (See Figure 6. This kind of statistical chart is often used to display a 
set of data scattering information, which can also be used to detect outliers (See the red plus sign "+" in the Figure 6).

Table 2. Univariate ANOVA.

\begin{tabular}{llllll}
\hline Source & SS & df & MS & F & Prob $>$ F \\
\hline Groups & $1.8373 \mathrm{e}+003$ & 10 & 183.7343 & 3.5369 & $1.3115 \mathrm{e}-004$ \\
Error & $4.9662 \mathrm{e}+004$ & 956 & 51.9482 & & \\
Total & $5.1500 \mathrm{e}+004$ & 966 & & & \\
\hline
\end{tabular}

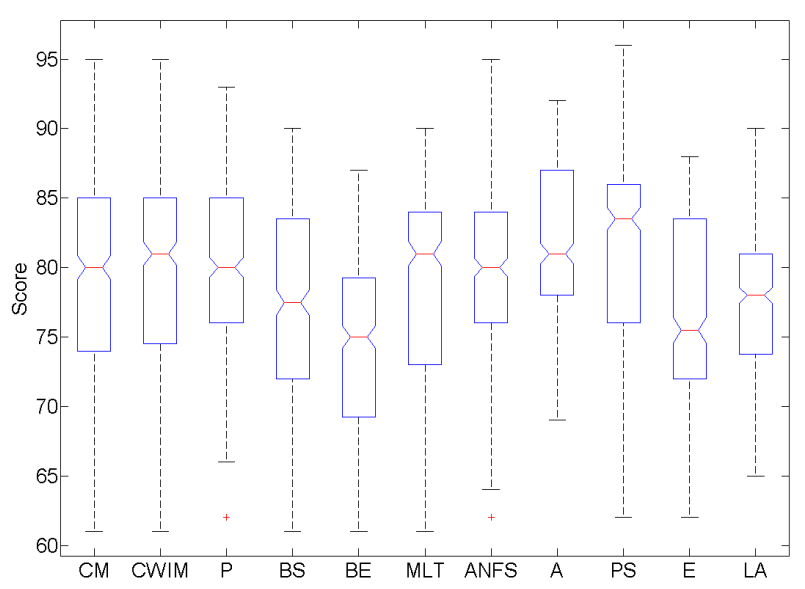

Figure 6. Boxplot generated by ANOVA function.

The results of variance analysis have shown that there are very significant differences in the test scores of students in different majors, but this does not mean that there are significant differences in the test scores of any two majors. Therefore, a two-to-two comparison test is needed, i.e. multiple comparison.

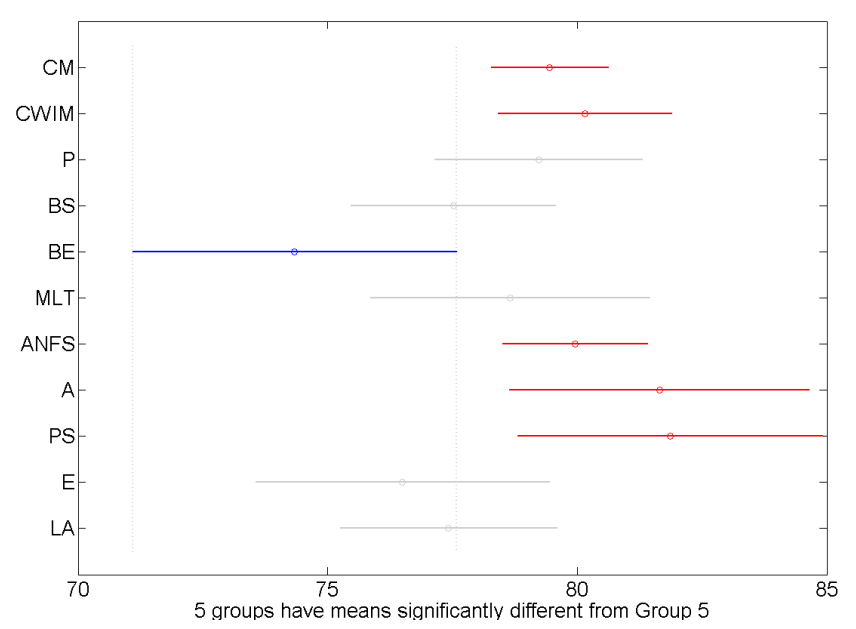

Figure 7. Graphic window for interactive multiple comparisons.

In Figure 7, there are some circles and lines. The circles represent the average scores of a major, while the lines represent the confidence intervals of the average professional values (confidence level or $95 \%$ of the previous ones). By looking at the position relationship of each line segment, we can judge whether the difference between the two professional averages is significant. If the projection positions of the two lines are overlapped, the difference between the mean values of the two majors is not significant (default significance level is 0.05). On the contrary, the difference between the two professional averages is significant. As shown in Figure 7, there is a significant difference between the test scores of Bioengineering (represented by blue line) and Clinical medicine, Chinese and western integrative medicine, Animal nutrition and feed science, Aquaculture as well as Pratacultural science (represented by red lines). In addition, the relationship between the average scores of various majors can also be visually reflected through this map.

\section{Conclusions}

With the help of statistical tools, it is found that the current teaching methods have a greater impact on the three majors of Bioengineering, Pratacultural science and Ecology, which means that the same teaching methods have an impact on different majors accounting for $27.27 \%$. At the same time, from the perspective of data analysis, we also found that the performance of Bioengineering students is significantly different from other five majors, such as Clinical Medicine, Chinese and Western integrative medicine, Animal nutrition and feed science, Aquaculture as well as Pratacultural science, under the same teaching mode. We believe that the main reason for such significant differences lies not in the major itself, because other similar majors have not appeared in this phenomenon, nor in the teaching model itself, because 11 different majors adopt the same teaching model, although it is undeniable that switching other teaching modes may help students to improve their learning and understanding of modern Chinese history, but we are more willing to believe that students of this major have problems with the understanding and acceptance of modern Chinese history. This is also the issue we will continue to focus on and investigate in the following study. From the research results of this paper, we hope to grasp the characteristics of students from different majors, study the corresponding teaching strategies, and help them better understand and learn related history courses. It is also hoped that this may help educators prepare their courses, and further understand and study the impact of modern Chinese history on the younger generation.

\section{Acknowledgements}

This work was supported by the Humanities and Social Sciences Foundation of Yangzhou University under Grant No. xj2018-14; The Spoc Course "Modern Chinese History" Construction Project of Yangzhou University in 2018; and the Achievements of China-Special Research Base of Yangzhou University.

\section{References}

[1] R. K. Schoppa (2011). Revolution and its past: identities and change in modern Chinese history, 3rd edition, Prentice Hall/Pearson. 
[2] D. G. Atwill, Y. R. Y. Atwill (2009). Sources in Chinese History: Diverse Perspectives from 1966 to the Present, Pearson Higher Education, 1st edition.

[3] J. G. Wang (2009). An Analysis of the special teaching mode of the course "Outline of modern Chinese history"-Taking Peking University as an example, Leading Journal of Ideological \& Theoretical Education, Issue 3, pp. 91-94. (in Chinese).

[4] J. G. Wang (2010). An Analysis of the special teaching mode of the course "Outline of modern Chinese history", Teaching and Research, Issue 6, pp. 94-96. (in Chinese).

[5] J. Israel (1999). Lianda: a Chinese university in war and revolution, Stanford University Press, 1st edition.

[6] The CPC Central Committee \& the State Council (2004). Opinions on further strengthening and improving ideological and political education for university students, Document ID 16. (in Chinese).

[7] L. X. Liu (2011). My cognition about the course teaching of the guidelines on modern Chinese history, Theory Learning, Issue 13, pp. 275-277. (in Chinese).

[8] J. Lim (2016). Modern Chinese history; Confucius in East Asia: Confucianism's history in China, Korea, Japan and Viet Nam, Asian Studies Review, Vol. 40: 1, pp. 137-138.
[9] J. Israel (2013). History of modern China, Semester at Sea Course Syllabus, HIEA 3559.

[10] T. Cheek (2015). The intellectual in modern Chinese history, Cambridge and New York: Cambridge University Press.

[11] J. Israel (1967). The red guards in historical perspective: continuity and change in the Chinese youth movement, The China Quarterly, Vol. 30, pp. 1-32.

[12] T. D. DuBois, J. Kiely eds. (2019). Fieldwork in modern Chinese history: a research guide, Routledge, 1st edition.

[13] J. A. Fogel (2015). Recent Japanese studies of modern Chinese history (II), Routledge.

[14] Y. Z. Ding, E. Mark (2018). How to write Chinese history in the twenty-first century: The impact of the "new Qing history" studies and Chinese responses, Chinese Studies in History, Vol. 51, pp. 70-95.

[15] H. N. Zhang (2019). Study on existing problems and suggested solutions of teaching in history of Chinese modern literature course, Advances in Social Science, Education and Humanities Research, Vol. 294, pp. 401-405.

[16] Z. M. Yang (2019). Exploration of heuristic teaching model of the course "Outline of modern and contemporary Chinese history" combining with specialty, Advances in Social Science, Education and Humanities Research, Vol. 342, pp. 268-272. 